\title{
Effects of Injection Rate Profile on Combustion Process and Emissions in a Diesel Engine
}

\author{
Fuqiang Bai, ${ }^{1}$ Zuowei Zhang, ${ }^{1}$ Yongchen Du, ${ }^{2}$ Fan Zhang, ${ }^{1}$ and Zhijun Peng ${ }^{2,3}$ \\ ${ }^{1}$ Key State Lab of Engines, Tianjin University, Tianjin, China \\ ${ }^{2}$ School of Engineering and Technology, University of Hertfordshire, Hertfordshire, UK \\ ${ }^{3}$ Faculty of Creative Arts, Technologies and Science, University of Bedfordshire, Luton, UK \\ Correspondence should be addressed to Zhijun Peng; jun.peng@beds.ac.uk
}

Received 3 February 2017; Accepted 7 May 2017; Published 21 June 2017

Academic Editor: Kalyan Annamalai

Copyright (C) 2017 Fuqiang Bai et al. This is an open access article distributed under the Creative Commons Attribution License, which permits unrestricted use, distribution, and reproduction in any medium, provided the original work is properly cited.

\begin{abstract}
When multi-injection is implemented in diesel engine via high pressure common rail injection system, changed interval between injection pulses can induce variation of injection rate profile for sequential injection pulse, though other control parameters are the same. Variations of injection rate shape which influence the air-fuel mixing and combustion process will be important for designing injection strategy. In this research, CFD numerical simulations using KIVA-3V were conducted for examining the effects of injection rate shape on diesel combustion and emissions. After the model was validated by experimental results, five different shapes (including rectangle, slope, triangle, trapezoid, and wedge) of injection rate profiles were investigated. Modeling results demonstrate that injection rate shape can have obvious influence on heat release process and heat release traces which cause different combustion process and emissions. It is observed that the baseline, rectangle (flat), shape of injection rate can have better balance between NOx and soot emissions than the other investigated shapes. As wedge shape brings about the lowest NOx emissions due to retarded heat release, it produces the highest soot emissions among the five shapes. Trapezoid shape has the lowest soot emissions, while its NOx is not the highest one. The highest NOx emissions were produced by triangle shape due to higher peak injection rate.
\end{abstract}

\section{Introduction}

High pressure common rail (HPCR) fuel injection system have provided significant benefit for optimizing air-fuel mixing and controlling ignition, combustion, and emissions in diesel engines. With the aid of electronic controllers, HPCR system allows adjustment of injection pressure, fuel injection amount, injection timing, and injection pulse number in each combustion cycle very flexibly [1-3]. Then optimized injection strategies can improve diesel engine combustion for low combustion noise, high combustion efficiency, and low emissions $[4,5]$. It can also provide postinjection for helping after-treatment system for regeneration. In recent years, as piezoinjectors are widely used for HPCR injection systems [6, 7]; injection timing and injection duration for each pulse can be controlled more precisely. Then multi-injection strategies are employed more and more for minimising emissions and fuel consumption.
When multi-injection strategies are employed, it has been realised that pressure waves that exist in HPCR system can result in significant effects on injection pressure and injection rate of sequent injection pulses $[8,9]$. When an injection pulse is completed, then the injector valve is closed; a pressure wave inside the fuel pipe does oscillate between the injector valve and the common rail. Even the pressure in the rail is rather steady during an injection, there is still pressure wave induced by a close of injector valve. Then the actual injection pressure and injection rate of sequent injection pulse will be changed by the pressure wave $[10,11]$. When the start timing of a sequent injection pulse is just at the peak of pressure wave, its injection pressure at the beginning will be higher than rail pressure. Otherwise, the injection pressure will be lower than the rail pressure. Then intervals between two adjacent injection pulses play very important role in managing the injection pressure and injection rate of sequent injection pulse. 
Currently, most injection strategies for diesel engines are designed to avoid different injection pressure between injection pulses, in order to have simple control to combustion processes. However, this kind of arrangements may not the best option for achieving optimal combustion and lowest emissions. Increased or reduced injection pressure and then varied injection rate and even injection rate shape for a sequent injection pulse may result in required improvement to air-fuel mixing and combustion rate under specific engine operation condition. For this issue, more investigations are still needed for achieving a clear idea how varied pressure, varied injection rate, and varied injection rate shape between injection pulses affect the combustion process and emissions.

Previous researches have suggested that effects of injection rates and their shape on air-fuel mixing and combustion processes are significantly important to organising diesel combustion $[12,13]$. Suh [13] has conducted experiments on a high speed direct injection (HSDI) diesel engine for which compression ratio is $15.3: 1$ reduced from $17.8: 1$ by modification of combustion chamber shape to investigate the effects of the twin-pilot-injection strategies on combustion performance and exhaust emissions. The study shows lower NOx emissions (up to $45.7 \%$ were observed), whereas soot generation level was almost unaltered in the multiple-injection case. Desantes et al. [14] investigated the effects of boot-type rate shapes on engine performance and emissions. From their two-part study, they concluded that long boot length and low boot pressure decreased NOx emissions but increased brake specific fuel consumption (BSFC) and soot emissions. Moreover, they discovered that boot-type rate shapes caused substantial change to the diffusion combustion regime as compared to the premixed combustion regime.

There have been a number of researches for examining injection rate of HPCR system, in particular for those single injection pulse. Multiple injection still lacks adequate understanding of the injection rate with flexible injection interval, in particular with consideration of pressure wave's effects. The present research is applying CFD numerical simulation to examine how varied injection rate will affect combustion process and emissions in diesel engines. A full combustion model of diesel engine including submodels of fuel injection, evaporation, air-fuel mixing, combustion, and emissions was validated by required experimental results. Then combustion process and emissions were investigated by considering five injection rate shapes which are possibly produced by HPCR systems under influence of pressure wave. Simulation results provide an insight into effects of injection rate shapes on diesel combustion and emissions.

\section{Numerical Model}

2.1. Model Description. Numerical simulations were conducted by using KIVA-3V code [15], which was improved by introducing several submodels, as shown in Table 1 . The submodels introduced have been tested by previous researchers [16] and it has been suggested that these new submodels are appropriate for diesel combustion. For resolving the turbulent flows in cylinder, the Renormalization Group (RNG) $k-\varepsilon$ turbulence model [17] was used. The heat transfer from the
TABLE 1: Computational submodels.

\begin{tabular}{lc}
\hline Turbulent model & RNG $k$ - $\varepsilon$ model [17] \\
Breakup model & KH-RT model [19] \\
Collision model & Nordin model [20] \\
Splash model & Han et al. model [21] \\
Heat transfer (wall) & Han-Reitz model [18] \\
Combustion & CHEMKIN [22] \\
Fuel chemistry & Reduced N-Heptane mechanism [23] \\
Soot model & Phenomenological model [24] \\
NOx mechanism & Extended Zeldovich mechanism [24] \\
\hline
\end{tabular}

wall was computed by the model developed by Han and Reitz [18] which counted the variations of both gas density and the turbulent Prandtl number in the boundary layer.

The spray process was modeled by a particle method, where the breakup processes of injected droplets were simulated by a Kelvin-Helmholtz Rayleigh-Taylor (KH-RT) model [19]. The collision model used here was one developed by Nordin [20] with improved grid independence. The interaction between spray and wall was represented by the model introduced by Han et al. [21], which considered the effects of gas density variation in simulating the size of secondary droplets in splashing.

The CHEMKIN [22] solver was coupled with KIVA-3V code to compute the chemical reaction. A reduced n-heptane reaction mechanism [23] was used to simulate diesel fuel chemistry, where the soot formation was solved by a phenomenological model, and NOx formation was represented with extended Zeldovich mechanism. Simulation results [24] has shown fair agreements with experimental results that could be achieved when the simulating method was used.

2.2. Engine Specifications. The engine used in this numerical study was a HSDI (high speed direct injection) diesel engine, same as the one used for experimental investigation by Herfatmanesh et al. [9]. The engine has four valves and a displacement of 0.55 litre per cylinder. Most of the engine parameters were maintained the same as those used in original experiments for the model validation except for some modifications made on the injector for further combustion simulations. The specifications of the engine are listed in Table 2.

2.3. Computational Grid. Since the diesel injector used in the research has 6 equally distributed orifices, the combustion chamber was represented by a $60^{\circ}$ sector grid with periodic boundary conditions, as shown in Figure 1. The grid for the cylinder volume at TDC (top dead centre) has approximately 25,231 hexahedral cells. The typical cell size is smaller than $3 \mathrm{~mm}$ in three dimensions, which is at the similar level used by Kim et al. [25]. Kim et al. also employed KIVA-3V for their simulation with grids $\left(2.2 \times 2.2 \times 3.0 \mathrm{~mm}^{3}\right)$ and their results have demonstrated adequate confidence of precision for combustion simulation. Therefore the grid used here is considered to yield reasonable accuracy for those predictions. 


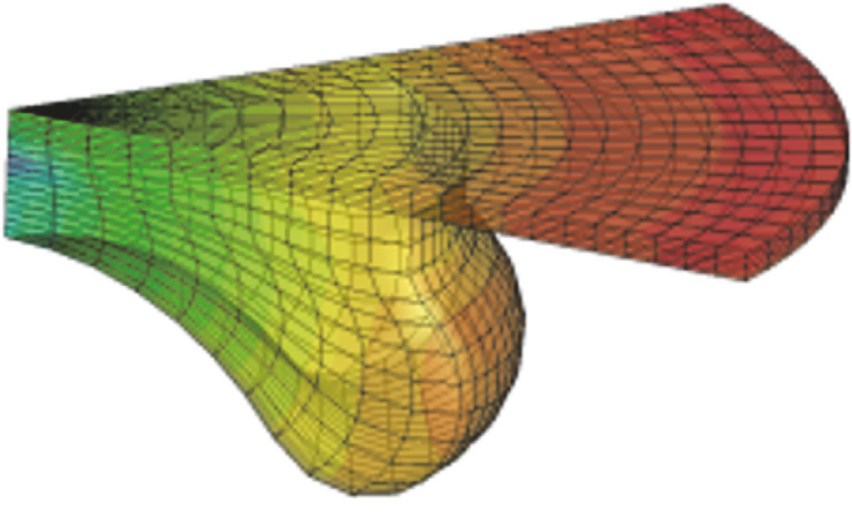

(a) In-cylinder volume at TDC

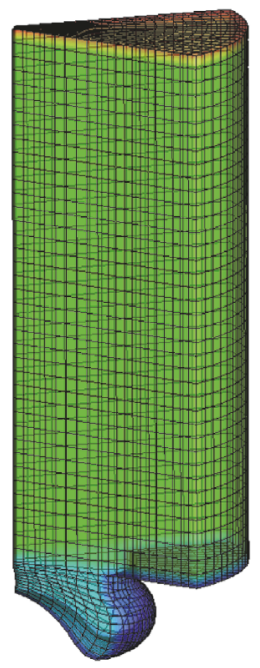

(b) In-cylinder volume at BDC

FIGURE 1: Computational mesh ((a) and (b) are not in same scale).

TABLE 2: Engine specifications for CFD simulation.

\begin{tabular}{|c|c|c|}
\hline Parameter & Unit & Detail \\
\hline Engine type & & $\begin{array}{c}2.2 \mathrm{~L} \\
\text { 4-cylinder } \\
\text { turbocharged }\end{array}$ \\
\hline Bore & $\mathrm{mm}$ & 86 \\
\hline Stroke & $\mathrm{mm}$ & 94.6 \\
\hline Valve number & & 4/cylinder \\
\hline Compression ratio & & $18: 1$ \\
\hline Turbocharger & & VGT \\
\hline Fuel injection system & & Common rail \\
\hline Injector hole diameter & $\mathrm{mm}$ & 0.12 \\
\hline Injector hole number & & 6/injector \\
\hline Peak torque & $\mathrm{Nm}$ & $\begin{array}{c}360 \\
@ 1500 \mathrm{rpm}\end{array}$ \\
\hline Peak power & $\mathrm{kW}$ & $\begin{array}{c}155 \\
@ 3800 \mathrm{rpm}\end{array}$ \\
\hline
\end{tabular}

2.4. Model Validation. The validation presented here was mainly combined with engine experimental results presented by previous researchers [16]. The fuel mass per cycle for the validation was $1 \mathrm{mg}$ for pilot injection and $21 \mathrm{mg}$ for main injection. The engine speed is $1800 \mathrm{rpm}$ and the injection pressure is $180 \mathrm{MPa}$. Other operating conditions were maintained the same as described in [16]. Figure 2 shows the comparison of the in-cylinder pressure between the simulation and experimental results. From the figure, it can be observed that a good agreement has been achieved between experimental and simulation results. For emissions which are shown in Figure 3, both NOx and soot emissions have been compared between experimental results and simulation by

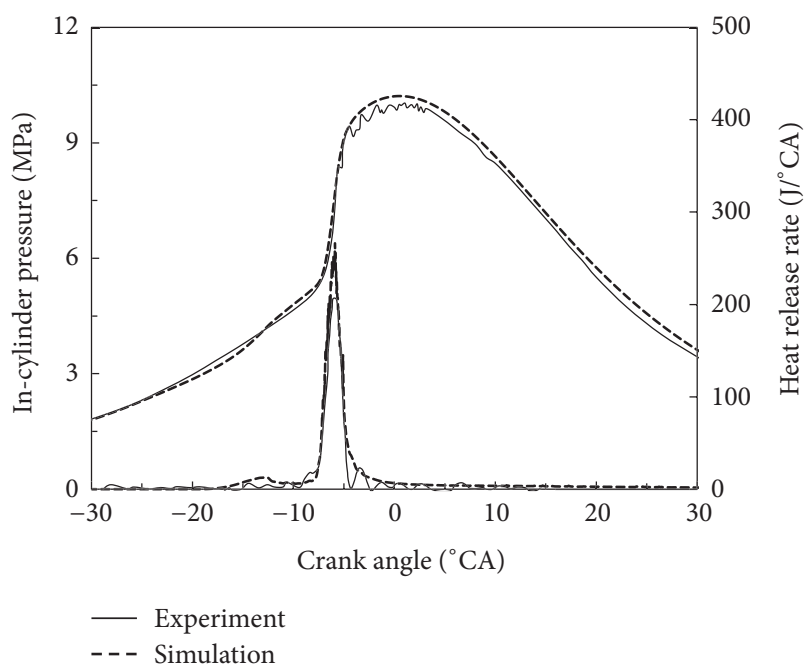

FIGURE 2: Comparison of in-cylinder pressure traces between experimental results and simulation.

varying the main injection timing. Those results show that the model can predict emissions with necessary accuracy.

\section{Simulation Conditions}

Previous experimental investigation has demonstrated that the sequential injection pulse can have very different injection rate profile. While other parameters are constant, increasing interval between injection pulses can result in the injection rate shape of sequential pulse gradually becoming more flat. The injection rate shape of sequent pulse for interval that increased from $750 \mu$ s to $2500 \mu$ s is very different, as shown in Figure 4. 


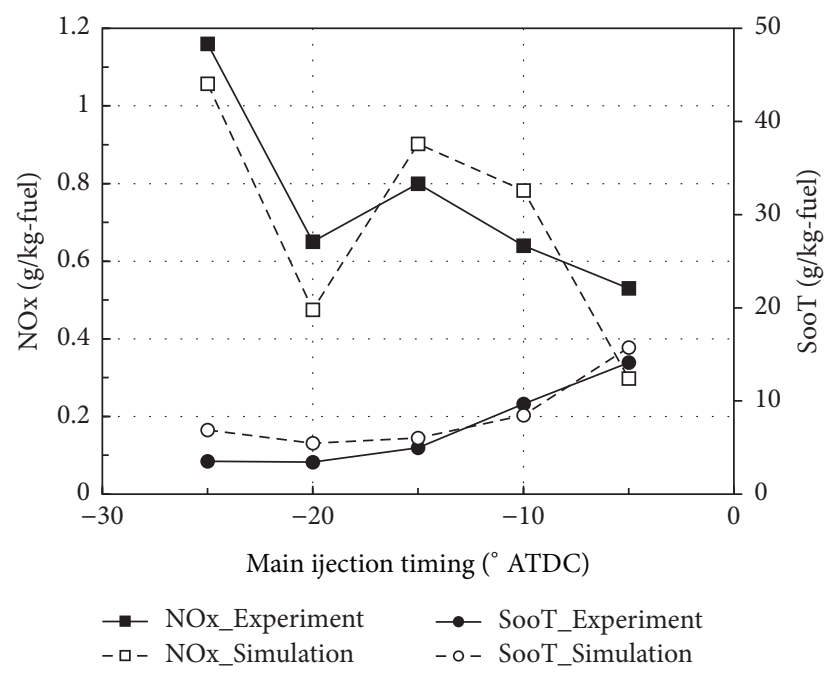

FIGURE 3: Comparison of NOx and soot emissions between experimental results and simulation.

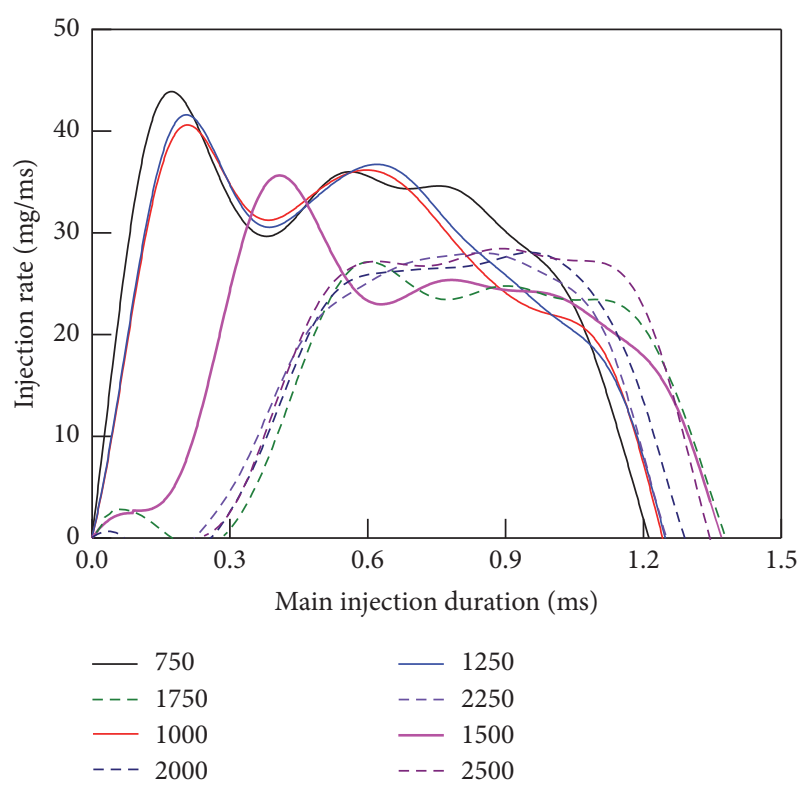

FIGURE 4: Experimental results of injection rates of second injection pulse (pulse width of $600 \mu \mathrm{s}-600 \mu \mathrm{s}$, interval shown in the figure, $80 \mathrm{MPa}$ injection pressure).

It can be seen in Figure 4 that average injection rates for different injection intervals are very different. With the increase of interval, the average injection rate keeps decreasing, in particular from 1250 to 1500 and then to $1750 \mu$ s. Those injection rates of intervals less than $1250 \mu$ s have similar trend and shape. They have a high peak at the start point and then second low peak after some reduction. The final stage has a smooth decreasing slope. The injection rate of $1500 \mu \mathrm{s}$ has some delay at the beginning and then displays similar trend as those of less than $1250 \mu \mathrm{s}$. After the interval increases over $1750 \mu \mathrm{s}$, all traces of injection rates have very similar profile, after a longer delay than that of $1500 \mu \mathrm{s}$, then having very slow

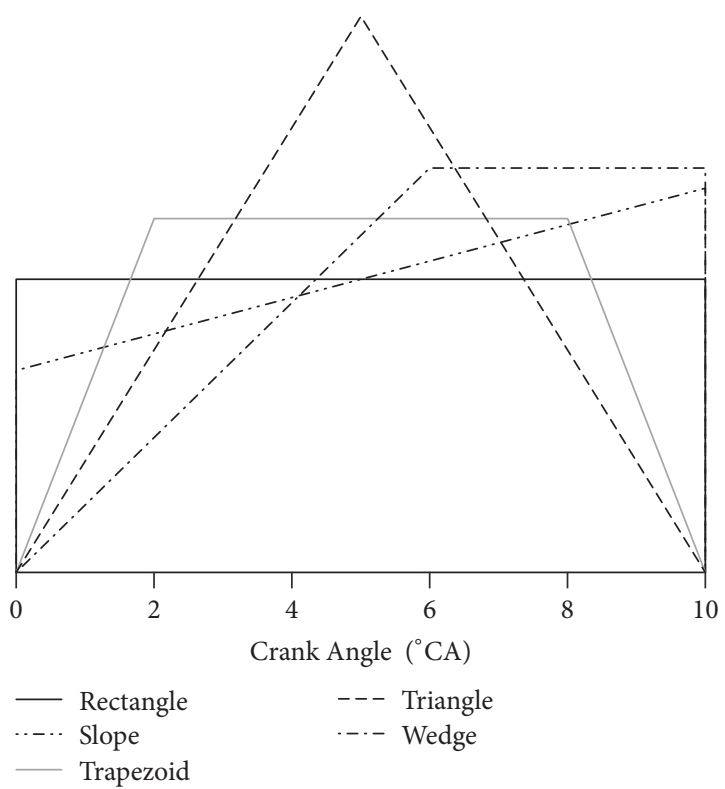

FIGURE 5: Different injection rate shape used for CFD simulation.

increase and long and flat persistence and finally decreasing quickly.

Considering practical injection rate shape's variation, in this research, five different injection rate shapes were selected to investigate the effects. As shown in Figure 5, among the five different injection rate shapes, the total fuel amount, pulse width, and average injection rate are maintained the same. While the rectangle shape has totally flat injection rate, the slope one has smooth increase across all pulse, and the wedge one has a little more steep increase at the beginning and then keeps flat at late stage. The triangle shape consists of only an increase stage and then a decrease stage with highest peak rate at the middle point. The trapezoid has the faster increase at beginning and fast decrease at finish stage but has some flat stage in between.

Although those shapes are considered here more for theoretical analysis, resemblant profiles may be produced under certain injection conditions, in particular, the trapezoid which is more close to most practical injection rate profiles. In order to study the effect of injection rate shapes, it was assumed that all the fuel was injected before TDC with the injection timing at $8.6^{\circ} \mathrm{CA}$ BTDC. The fuel amount is $49.2 \mathrm{mg}$.

\section{Result and Discussions}

4.1. Effects on Combustion Process and Heat Release Rate. The in-cylinder pressure traces and heat release rate traces for five cases are presented in Figure 6. As the rectangle one has the highest injection rate at the start point, its ignition timing is the earliest one and at the beginning its heat release rate has a faster increase than other shapes. As the triangle one has the highest injection rate close to TDC, it produces the highest heat release rate near TDC.

During late stage of combustion, as the rectangle one and slope one do not get further increase too much of injection 


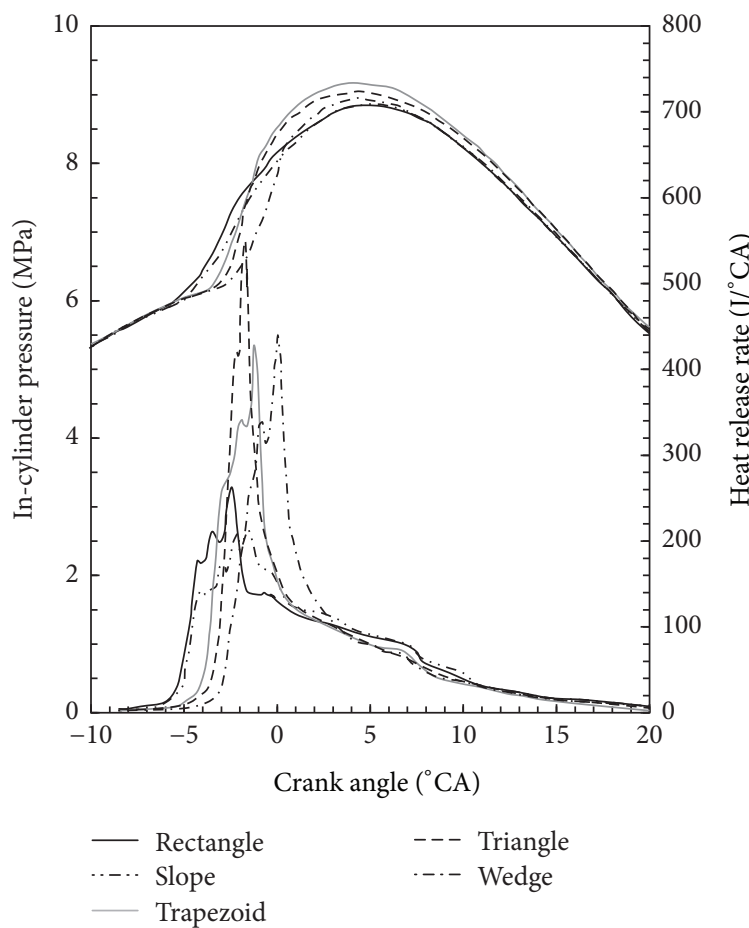

Figure 6: Simulated in-cylinder pressure traces and heat release rate traces for five different injection rate shapes.

rate, increases in heat release rates are not so obvious compared to other three shapes. The wedge one has a later peak at late stage because of its highest injection rate for a long time at the late injection stage.

Basic process can be analysed by inspecting the incylinder temperature distribution. The results at four different crank angles are shown in Table 3. At the beginning and late stage of fuel injection is shown that in-cylinder temperature distributions are very similar for all the five shapes. But by the mid-stage combustion (about $5^{\circ} \mathrm{CA}$ ATDC), triangle and trapezoid have obviously bigger areas of high temperature than other three shapes. This may be due to the higher injection rate during middle injection stage for those two shapes.

At the late stage of combustion (such as $10^{\circ} \mathrm{CA}$ ATDC as shown in Table 3), all five have similar temperature distribution, although wedge has the smallest area of high temperature (red colour) and slope has the smallest area of mid-high temperature (yellow colour). In Table 3 , it can be observed that slope and wedge shapes have still obvious fuel spray at TDC, while other shapes' injection have almost totally stopped. This may be due to higher injection rate at late injection stage for slope and wedge shape.

By analysing the in-cylinder temperature traces from in-cylinder pressure traces for five shapes, from results as shown in Figure 7, it can be observed that they are consistent with information shown in Table 3. Although the initial temperature increase did not take place too early for trapezoid and triangle shapes, their temperatures increase very rapidly and maintain high values than other three shapes. For wedge shape, its temperature is not so high although its peak value of

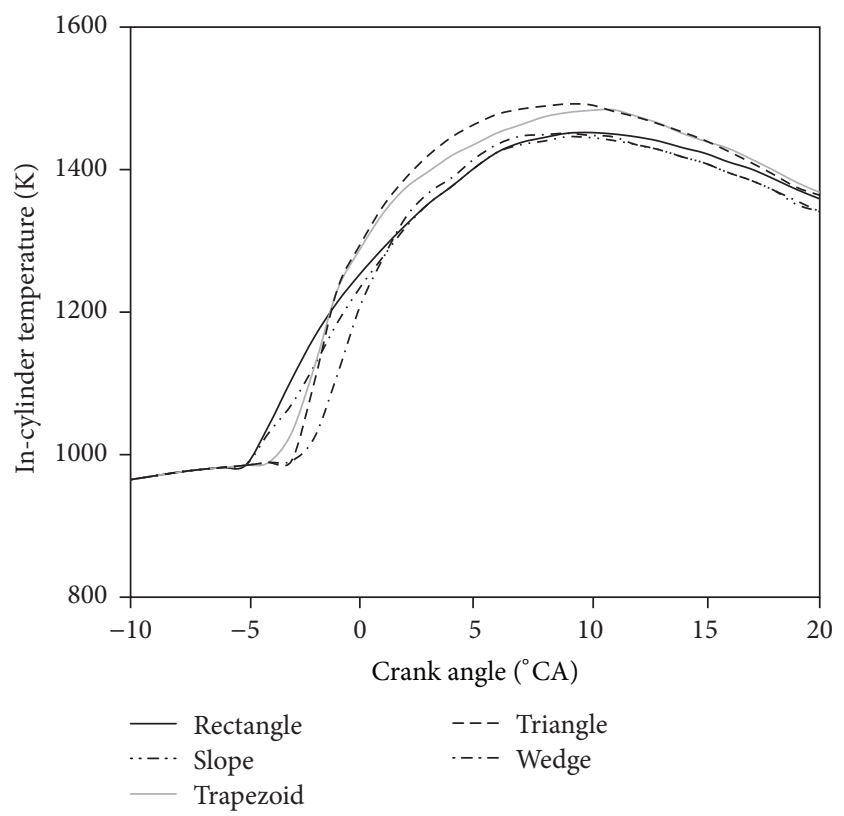

FIGURE 7: Simulated in-cylinder temperature for five different injection rate shapes.

heat release is about twice higher than that of rectangle shape. The main reason may be that its most heat release takes place at a later stage compared to the other shapes.

4.2. Effects on Emissions. Based on the difference of in-cylinder peak temperature (as shown in Figure 7), the triangle shape shows the highest NOx emissions and the wedge shows the lowest NOx emissions, as shown in Figure 8. A special point is that the rectangle shape has lower peak temperature than the slope one, but its NOx emissions are higher. By checking the in-cylinder temperature distributions of two shapes (as shown in Table 3), it can be observed that the high temperature area of the rectangle shape is bigger than the slope one at the crank angle where the combustion will be completed.

Soot and NOx emissions as shown in Figure 9 basically show their relation as trade-off. But triangle one which has the highest NOx emissions does not follow the trend to have lowest soot emissions. By reviewing the heat release rates, it can be seen that its peak heat release rate is too early compared to the others. The reason for the more soot emissions is that a lot of fuel was injected due to the highest injection rate. Hence, a liquid film may be formed inside the piston bowl as shown in Table 3. If both NOx and soot emissions are considered as important factors, the rectangle shape can have better compromise between them, while the triangle shape is the worst case. For practical applications, this means that high peak in injection rate shape should be avoided.

Figure 10 shows the results of $\mathrm{CO}$ and $\mathrm{HC}$ emissions. For triangle shape, because it has the highest in-cylinder temperature, it $\mathrm{HC}$ emissions are the lowest one. But its $\mathrm{CO}$ emissions are the highest one. This may be due to the poor airfuel mixing while most fuel is injected during middle stage 
TABLE 3: In-cylinder temperature distributions at $8^{\circ} \mathrm{CA}$ BTDC, TDC, $5^{\circ} \mathrm{CA}$ ATDC, and $10^{\circ} \mathrm{CA}$ ATDC for five different injection rate shapes.

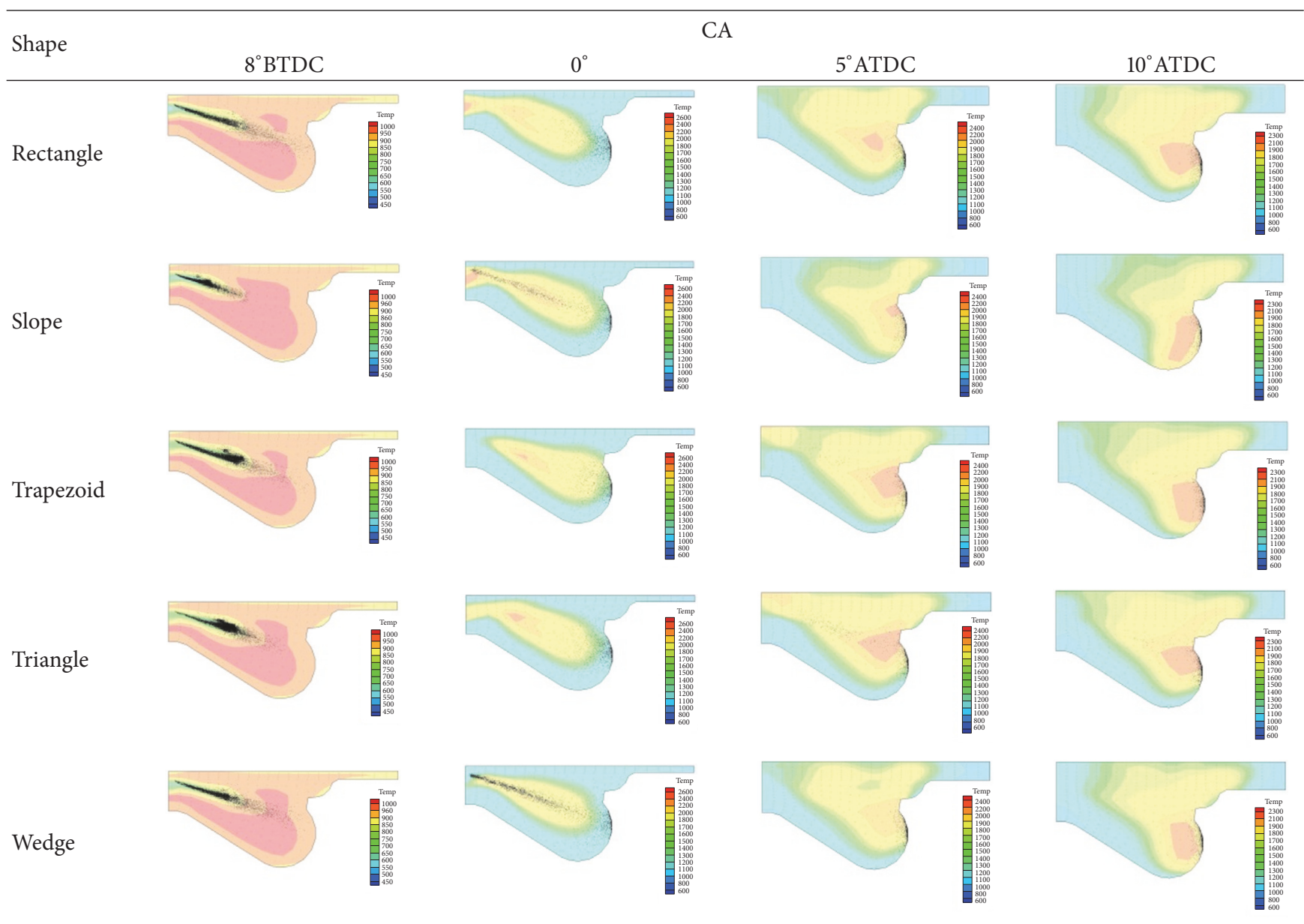

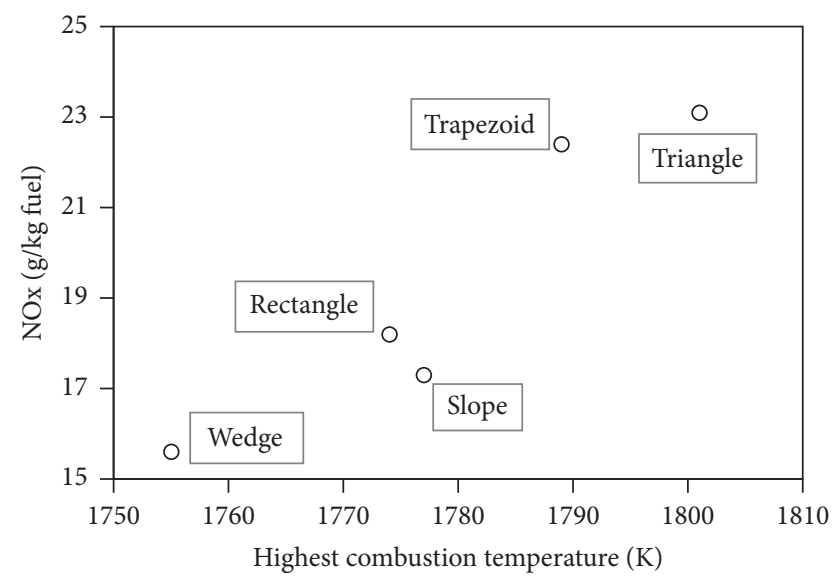

FIGURE 8: Simulation results of NOx emissions for five different injection rate shapes.

with very high injection rate. The wedge shape has also very high $\mathrm{CO}$ emissions since it has high injection rate at the late injection stage. Its $\mathrm{HC}$ emissions are the highest one. This is obviously due to its low combustion temperature. Slope and rectangle have low $\mathrm{CO}$ emissions but high $\mathrm{HC}$ emissions. This

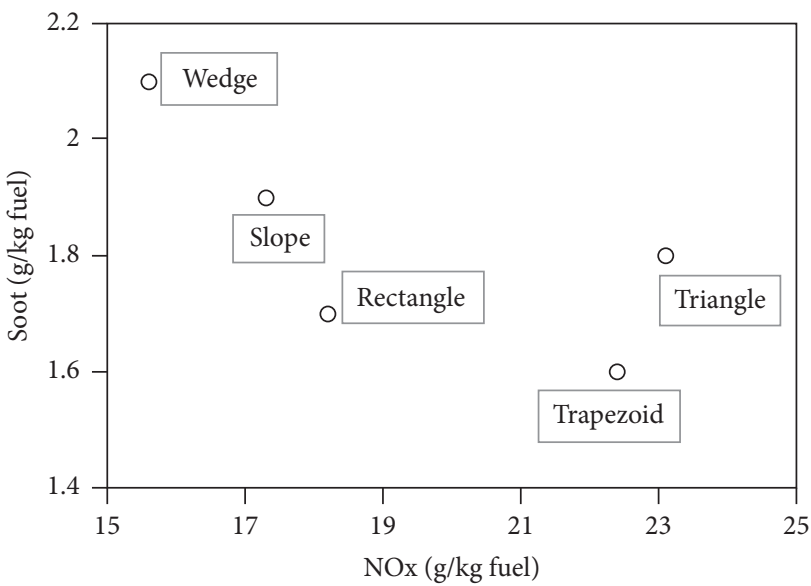

FIGURE 9: Simulation results for soot and NOx emissions of five different injection rate shapes.

may be because their injection rates are flat compared to the other shapes. In the one hand, the flat injection rate may result in better mixing, then producing lower $\mathrm{CO}$ emission. On the other hand, their low combustion temperatures contribute to high $\mathrm{HC}$ emissions. It can be noticed that slope has both lower 


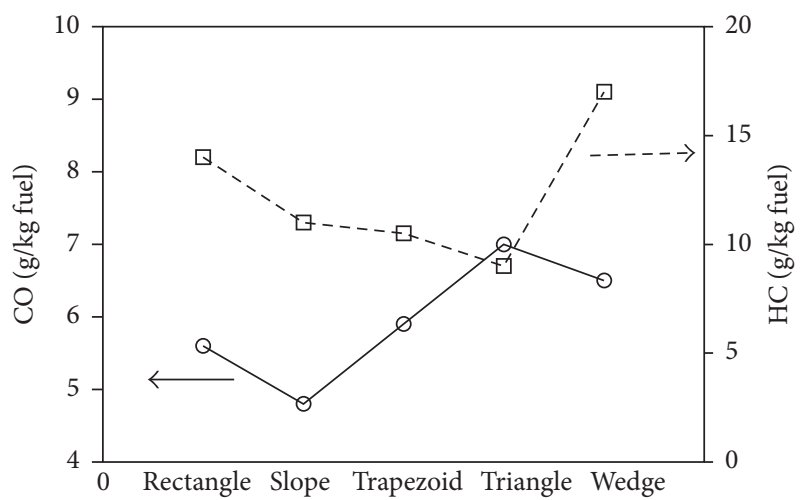

Figure 10: Simulation results for $\mathrm{CO}$ and $\mathrm{HC}$ emissions of five different injection rate shapes.

$\mathrm{CO}$ and $\mathrm{HC}$ emissions than rectangle shape. This suggests slow increase of injection rate can benefit both $\mathrm{HC}$ and $\mathrm{CO}$ emissions, compared to totally flat injection rate.

Having this set of simulations suggests that different injection rate shape for individual injection pulse can also have influence on combustion process and emissions. The rectangle shape can have better balance between NOx and soot emissions, because other shapes with higher injection rate at some point (temporal) will result in higher NOx or soot emissions.

\section{Conclusions}

In the research work presented, influences of variations of injection rate shape caused by different injection intervals were examined by numerical simulation based on KIVA-3V CFD code. From the results, the following conclusions have been derived:

(i) Injection rate shape has an influence on diesel combustion process, in-cylinder mixing, heat release rate, and in-cylinder temperature distribution. The triangle shape has the highest peak combustion temperature due to too high injection rate at some injection point. The wedge shape's combustion temperature is the lowest across most combustion stages due to its late ignition timing.

(ii) Rectangle shape can have better balance between NOx and soot emissions, while other shapes with higher injection rate at some point (temporal) will result in higher NOx or soot emissions.

(iii) The triangle shape produces the highest NOx emissions due to the highest combustion temperature. The trapezoid shape shows the lowest soot emissions due to both better mixing and high combustion temperature.

(iv) The slope shape has the lowest $\mathrm{CO}$ emissions and not very high $\mathrm{HC}$ emissions. Regarding $\mathrm{CO}$ and $\mathrm{HC}$ emissions, it is better than rectangle shape.

\section{Acronyms}

ATDC: After top dead centre

BTDC: Before top dead centre

CA: Crank angle

CFD: Computational fluid dynamics

CO: Carbon monoxide

EOI: End of injection

HC: Hydrocarbon

HPCR: High pressure common rail

HRR: Heat release rate

HSDI: High speed direct injection

NOx: Nitrogen oxides

PM: Particulate matters

TDC: Top dead centre.

\section{Conflicts of Interest}

The authors declare that there are no conflicts of interest regarding the publication of this paper.

\section{References}

[1] J. Hinkelbein, C. Sandikcioglu, S. Pischinger, M. Lamping, and T. Körfer, "Control of the Diesel Combustion Process via Advanced Closed Loop Combustion Control and a Flexible Injection Rate Shaping Tool," SAE Technical Paper, vol. 24, article 0114, 2009.

[2] X. Li, H. Zhou, L. M. Zhao, L. Su, H. Xu, and F. Liu, "Effect of split injections coupled with swirl on combustion performance in DI diesel engines," Energy Conversion and Management, vol. 129, pp. 180-188, 2016.

[3] P. Dimitriou, Z. Peng, W. Wang, B. Gao, and M. Wellers, "Effects of advanced injection strategies on the in-cylinder airfuel homogeneity of diesel engines," Proceedings of the Institution of Mechanical Engineers, Part D: Journal of Automobile Engineering, vol. 229, no. 3, pp. 330-341, 2015.

[4] B. Rohani and C. Bae, "Effect of exhaust gas recirculation (EGR) and multiple injections on diesel soot nano-structure and reactivity," Applied Thermal Engineering, vol. 116, pp. 160-169, 2017.

[5] A. Gharehghani, S. M. Mirsalim, and S. A. Jazayeri, "Numerical and experimental investigation of combustion and knock in a dual fuel Gas/Diesel compression ignition engine," Journal of Combustion, vol. 2012, Article ID 504590, 10 pages, 2012.

[6] H. Nouraei, R. Ben-Mrad, and A. N. Sinclair, "Development of a Piezoelectric Fuel Injector," IEEE Transactions on Vehicular Technology, vol. 65, no. 3, pp. 1162-1170, 2016.

[7] J. Kim, J. Kim, S. Jeong, S. Han, and J. Lee, "Effects of different piezo-acting mechanism on two-stage fuel injection and CI combustion in a CRDi engine," Journal of Mechanical Science and Technology, vol. 30, no. 12, pp. 5727-5737, 2016.

[8] A. E. Catania, A. Ferrari, M. Manno, and E. Spessa, "Experimental investigation of dynamics effects on multiple-injection common rail system performance," Journal of Engineering for Gas Turbines and Power, vol. 130, no. 3, Article ID 032806, 2008.

[9] M. R. Herfatmanesh, Z. Peng, A. Ihracska, Y. Lin, L. Lu, and C. Zhang, "Characteristics of pressure wave in common rail fuel injection system of high-speed direct injection diesel engines," Advances in Mechanical Engineering, vol. 8, no. 5, pp. 1-8, 2016.

[10] J. Baumann, U. Kiencke, T. Schlegl, and W. Oestreicher, "Practical feasibility of measuring pressure waves in Common Rail 
injection systems by magneto-elastic sensors," SAE Technical Papers, vol. 1, article 0891, 2006.

[11] A. De Risi, F. Naccarato, and D. Laforgia, "Experimental analysis of common rail pressure wave effect on engine emissions," SAE Technical Papers, vol. 1, article 0373, 2005.

[12] C. Y. Choi and R. D. Reitz, "Modeling the effects of oxygenated fuels and split injections on DI diesel engine performance and emissions," Combustion Science and Technology, vol. 159, no. 1, pp. 169-198, 2000.

[13] H. K. Suh, "Study on the twin-pilot-injection strategies for the reduction in the exhaust emissions in a low-compression-ratio engine," Proceedings of the Institution of Mechanical Engineers, Part D: Journal of Automobile Engineering, vol. 228, no. 3, pp. 335-343, 2014.

[14] J. M. Desantes, J. Benajes, S. Molina, and C. A. González, “The modification of the fuel injection rate in heavy-duty diesel engines. Part 1: Effects on engine performance and emissions," Applied Thermal Engineering, vol. 24, no. 17-18, pp. 2701-2714, 2004.

[15] A. Amsden, "KIVA-3V: A block-structured KIVA program for engines with vertical or canted valves," Technical Report for Los Alamos National Laboratorym LA-13313-MS, Los Alamos, NM, USA, 1997.

[16] Z. Peng, B. Liu, W. Wang, and L. Lu, "CFD investigation into diesel PCCI combustion with optimized fuel injection," Energies, vol. 4, no. 3, pp. 517-531, 2011.

[17] Z. Han and R. D. Reitz, "Turbulence modeling of internal combustion engines using RNG k-e models," Combustion Science and Technology, vol. 106, no. 4, pp. 267-276, 1995.

[18] Z. Han and R. D. Reitz, "A temperature wall function formulation for variable-density turbulent flows with application to engine convective heat transfer modeling," International Journal of Heat and Mass Transfer, vol. 40, no. 3, pp. 613-625, 1997.

[19] L. M. Ricart and R. D. Reltz, "Comparisons of diesel spray liquid penetration and vapor fuel distributions with in-cylinder optical measurements," Journal of Engineering for Gas Turbines and Power, vol. 122, no. 4, pp. 588-595, 2000.

[20] N. Nordin, Complex chemistry modeling of diesel spray combustion. Thesis [Ph.D. thesis], Chalmers University of Technology, Goteborg, Sweden, 2001.

[21] Z. Han, Z. Xu, and N. Trigui, "Spray/wall interaction models for multidimensional engine simulation," International Journal of Engine Research, vol. 1, no. 1, pp. 127-146, 2000.

[22] R. Kee, F. Rupley, E. Meeks, and J. Miller, "CHEMKIN-III: A FORTRAN chemical kinetics package for the analysis of gas-phase chemical and plasma kinetics," Technical Report for Sandia National Laboratories SAND96-8216, Albuquerque, NM, USA, 1996.

[23] A. Patel, S.-C. Kong, and R. D. Reitz, "Development and validation of a reduced reaction mechanism for HCCI engine simulations," SAE Technical Papers, vol. 1, article 0558, 2004.

[24] M. Jia, Z.-J. Peng, and M.-Z. Xie, "Numerical investigation of soot reduction potentials with diesel homogeneous charge compression ignition combustion by an improved phenomenological soot model," Proceedings of the Institution of Mechanical Engineers, Part D: Journal of Automobile Engineering, vol. 223, no. 3, pp. 395-412, 2009.

[25] Y.-J. Kim, S. H. Lee, and N.-H. Cho, "Effect of air motion on fuel spray characteristics in a gasoline direct injection engine," SAE Technical Papers, vol. 1, article 0177, 1999. 


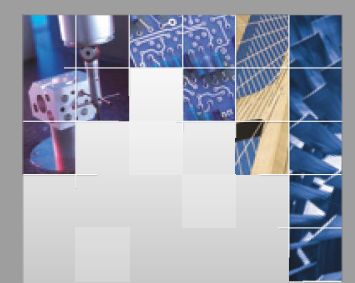

\section{Enfincering}
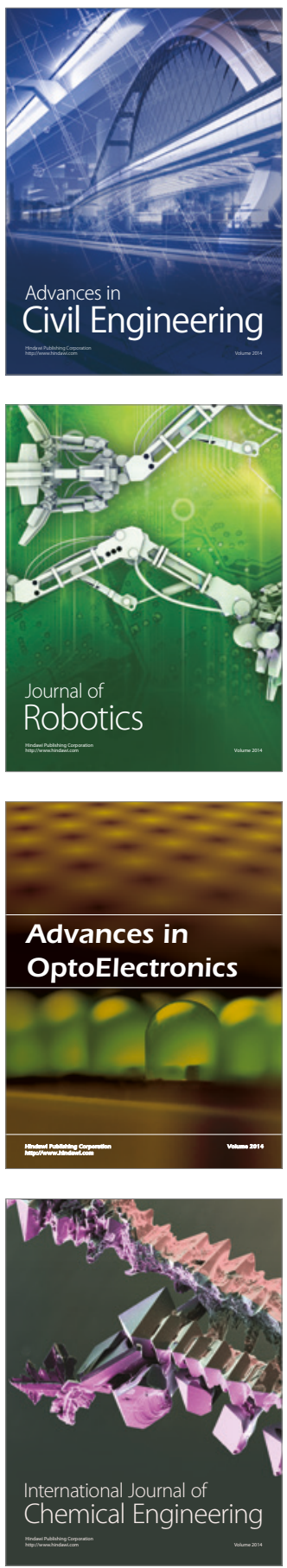

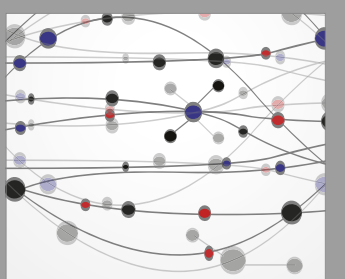

The Scientific World Journal

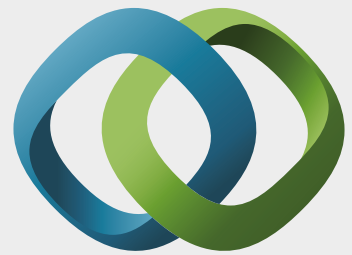

\section{Hindawi}

Submit your manuscripts at

https://www.hindawi.com
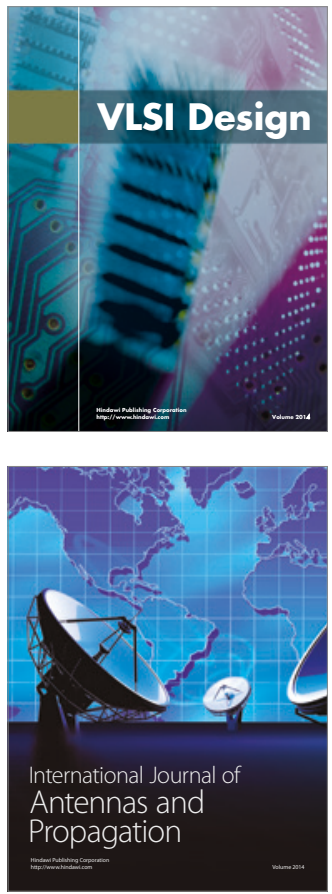

\section{Rotating}

Machinery
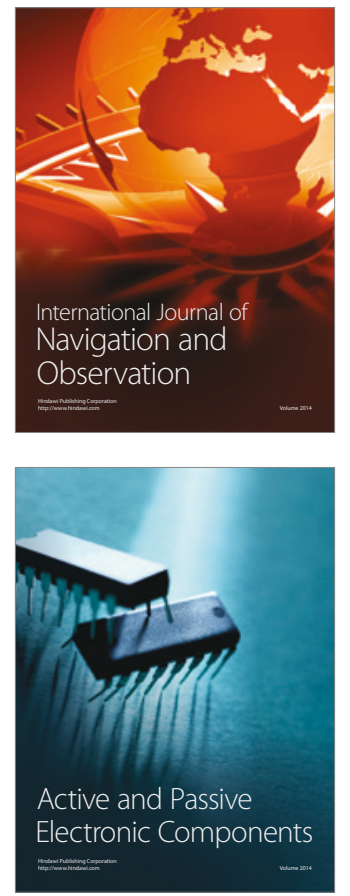
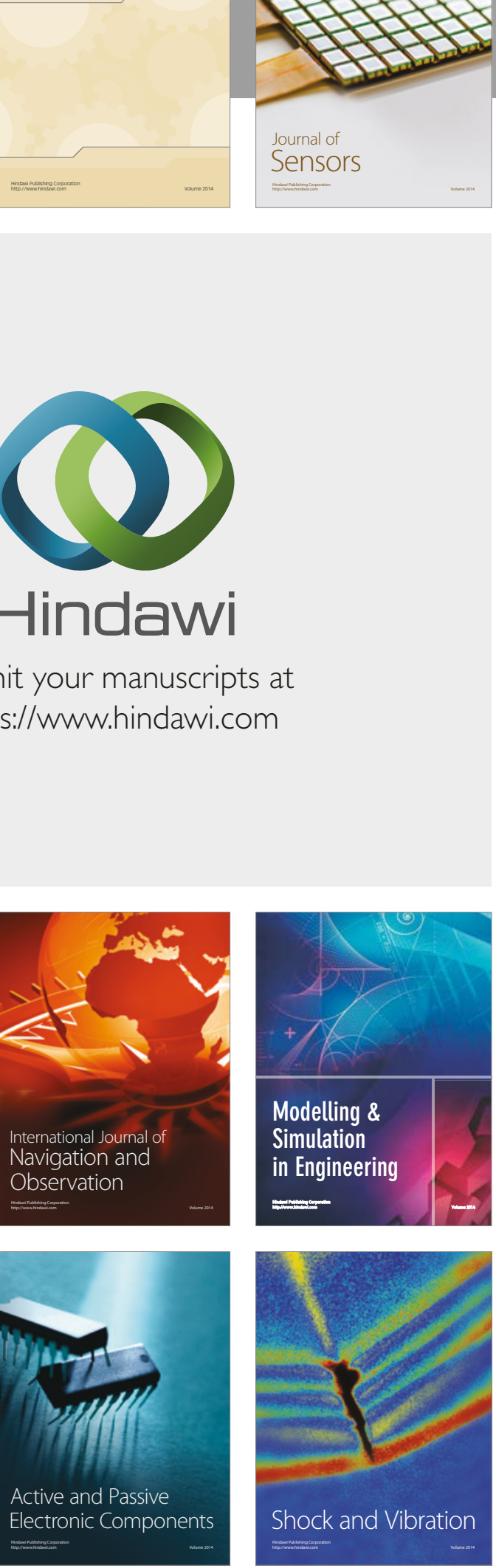
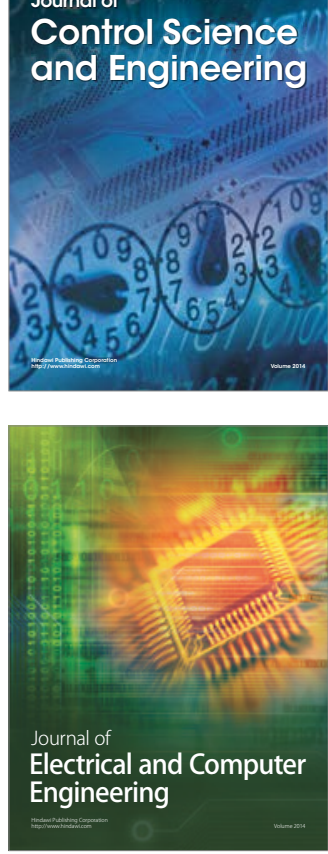

Distributed

Journal of

Control Science

and Engineering
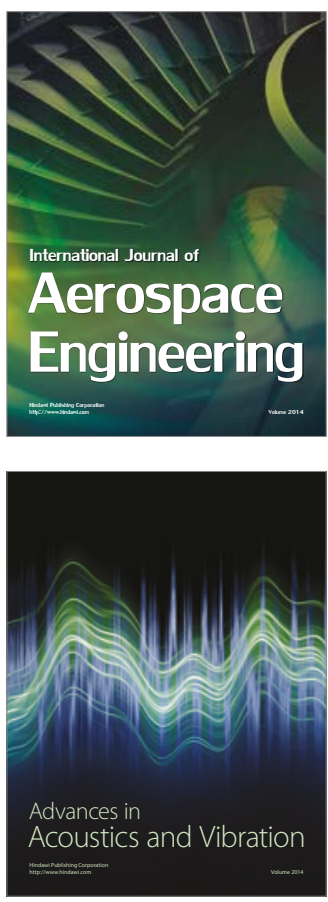

Sensor Networks 